\title{
AREIA MOVEDIÇA, [SALA DE ESCUTA], FUNDO DO AR
}

\section{Raquel Stolf*}

\begin{abstract}
Resumo: Alguns extratos de três trabalhos artísticos por mim desenvolvidos: Areia movediça (texto-obra, publicado no Jornal de Borda n.1, 2015); Assonâncias de silêncios [sala de escuta] (instalação sonora, 2008-2010) e Fundo do ar [caderno-abismo] (instalação, 2013-2015). No processo desses trabalhos são investigadas relações entre processos de escrita e situações de leitura e escuta (ou "espécies de escutas", modulações entre o sonoro e o acústico), em intersecções entre palavra e silêncio (em tentativas de proposições de vazio), pensando também suas imobilidades/passagens (ou suas passagens imóveis) e suas opacidades.
\end{abstract}

Palavras-chave: Processos de escrita. Situações de escuta. Silêncio. Ruído. Vazio.

* Artista, pesquisadora e professora nos cursos de Graduação e Pós-Graduação em Artes Visuais da Universidade do Estado de Santa Catarina - UDESC. Mestre e doutora em Artes Visuais (Poéticas Visuais) pela Universidade Federal do Rio Grande do Sul - UFRGS. E-mail: raquel.stolf@gmail.com. 


\section{Areia movediça1}

o presente bloco pode ser lido em voz alta, em espaços abertos ou fechados, com ou sem respirações auditivas (público)

STOLF, Raquel. Areia movediça, [Sala de escuta], Fundo do ar. Crítica Cultural - Critic, Palhoça, SC, v. 11, n. 2, p. 225-239, jul./dez. 2016. 
de orelha em orelha, um ruído em fase pré-larval.

as letras ainda não saem do lugar. situam-se numa espécie

de área semitransparente, antes de a palavra sair pela boca.

ovo de letra / boca sentada

(antes) (depois)

antes de sair pela boca, a palavra fica ali grudada, na garganta, atrás da

cabeça ou sob a pele, como um grão sublingual. segundo várias confissões

e suposições, ela pode desaparecer, como um soluço do avesso, se a

velocidade da saída for mais lenta que a velocidade da entrada (de ar).

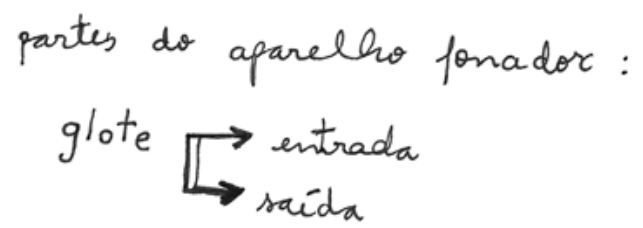

$$
\begin{aligned}
& 1 \text { gole de tempo } \\
& \text { 10 ba de caneta }
\end{aligned}
$$

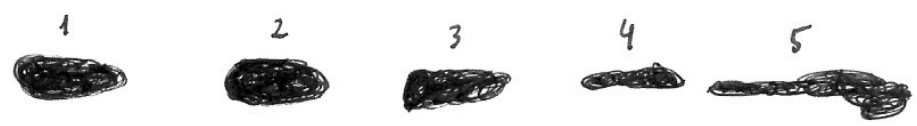



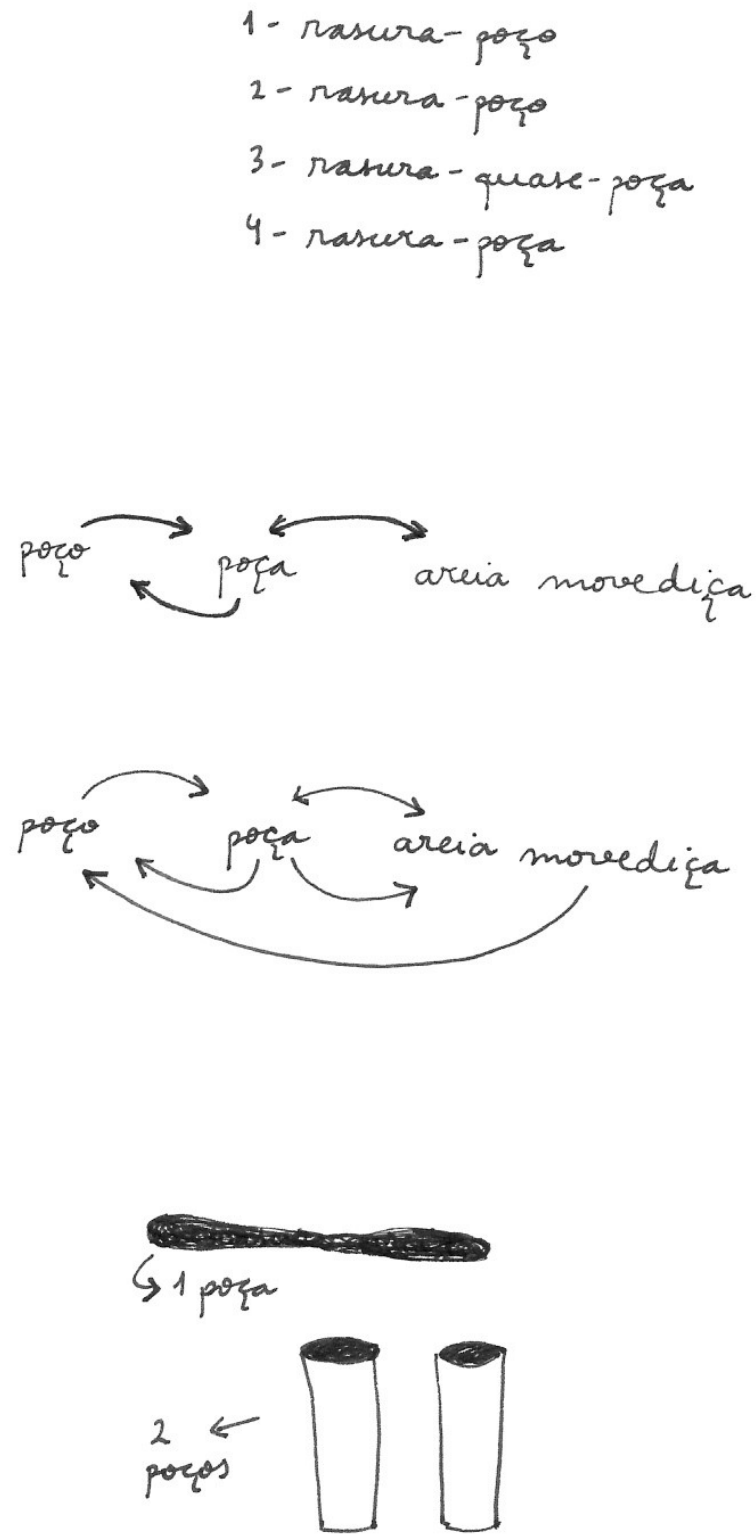

sobre o risco de uma palavra ou de um ruído sair por um ouvido e entrar pelo outro:

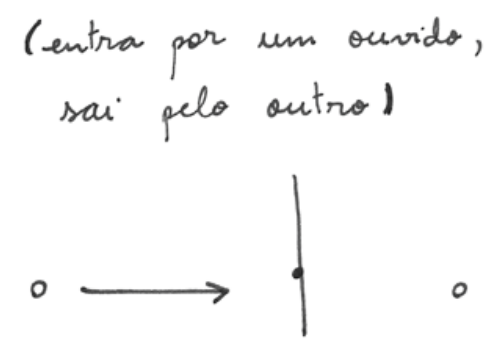

- imfra (vulto)

- ultra (micro) 
táticas para estancar o que entra de um lado: construir uma parede dentro da cabeça.

(ela pode ser de pele, como uma pálpebra. ou ser uma nuvem de composição incerta, que se forma assim que a onda sonora entra pelo ouvido)

as paredes têm orilhas.
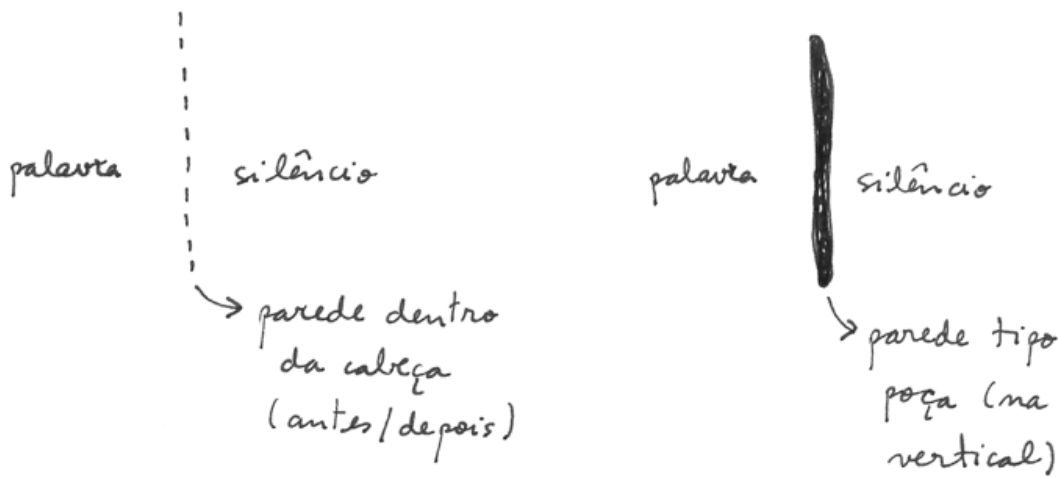
Assonâncias de silêncios [sala de escuta] ${ }^{2}$ 


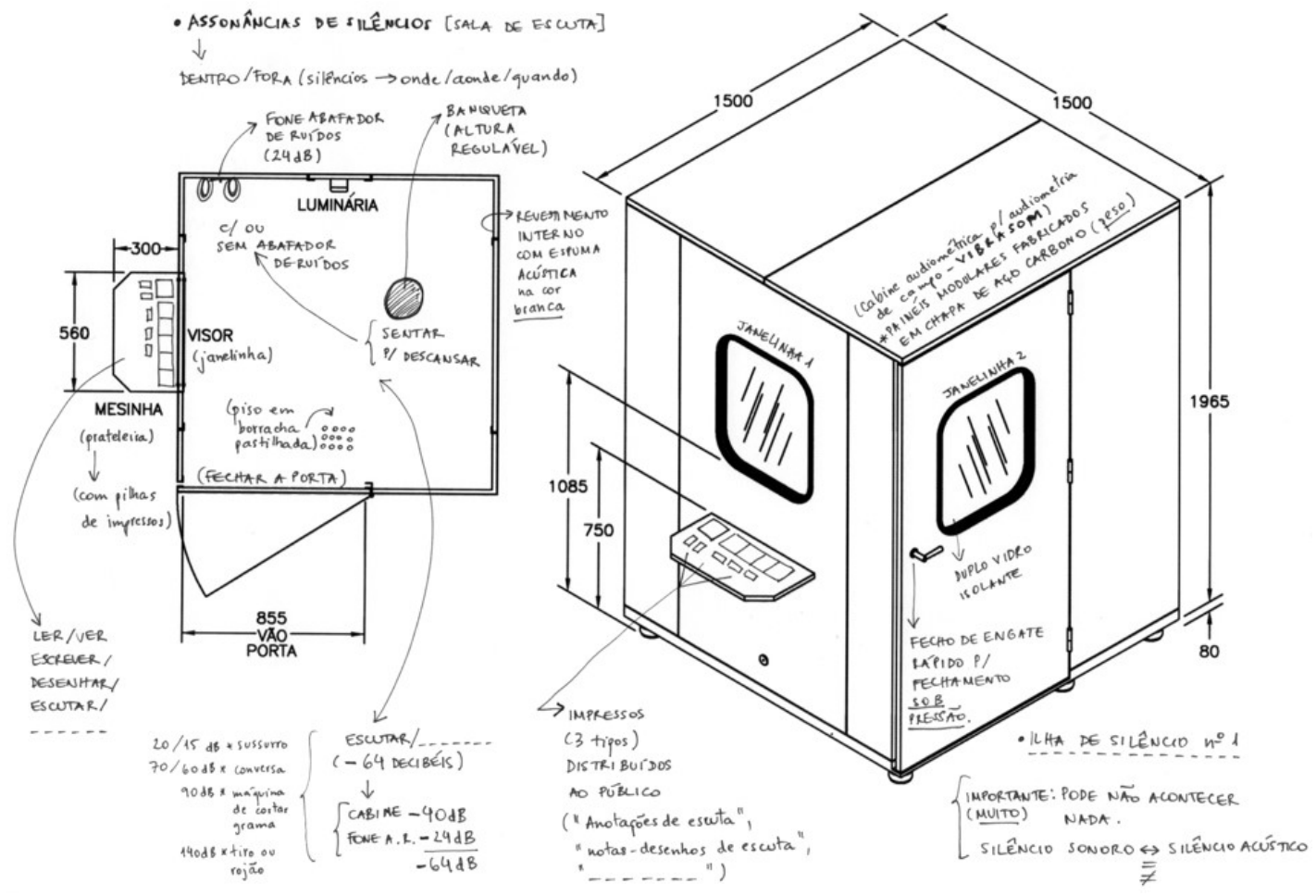



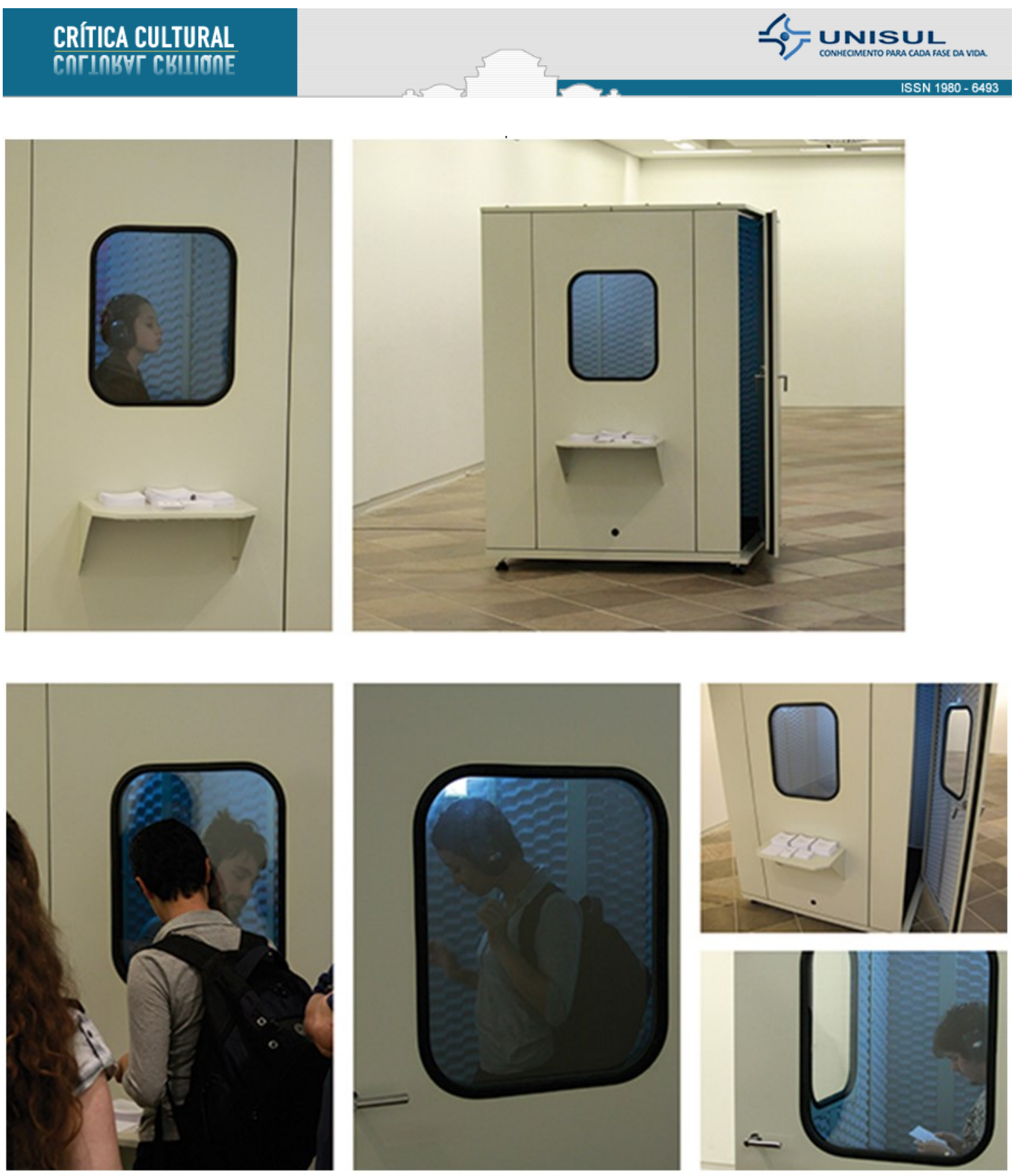

- silencio embrulhado
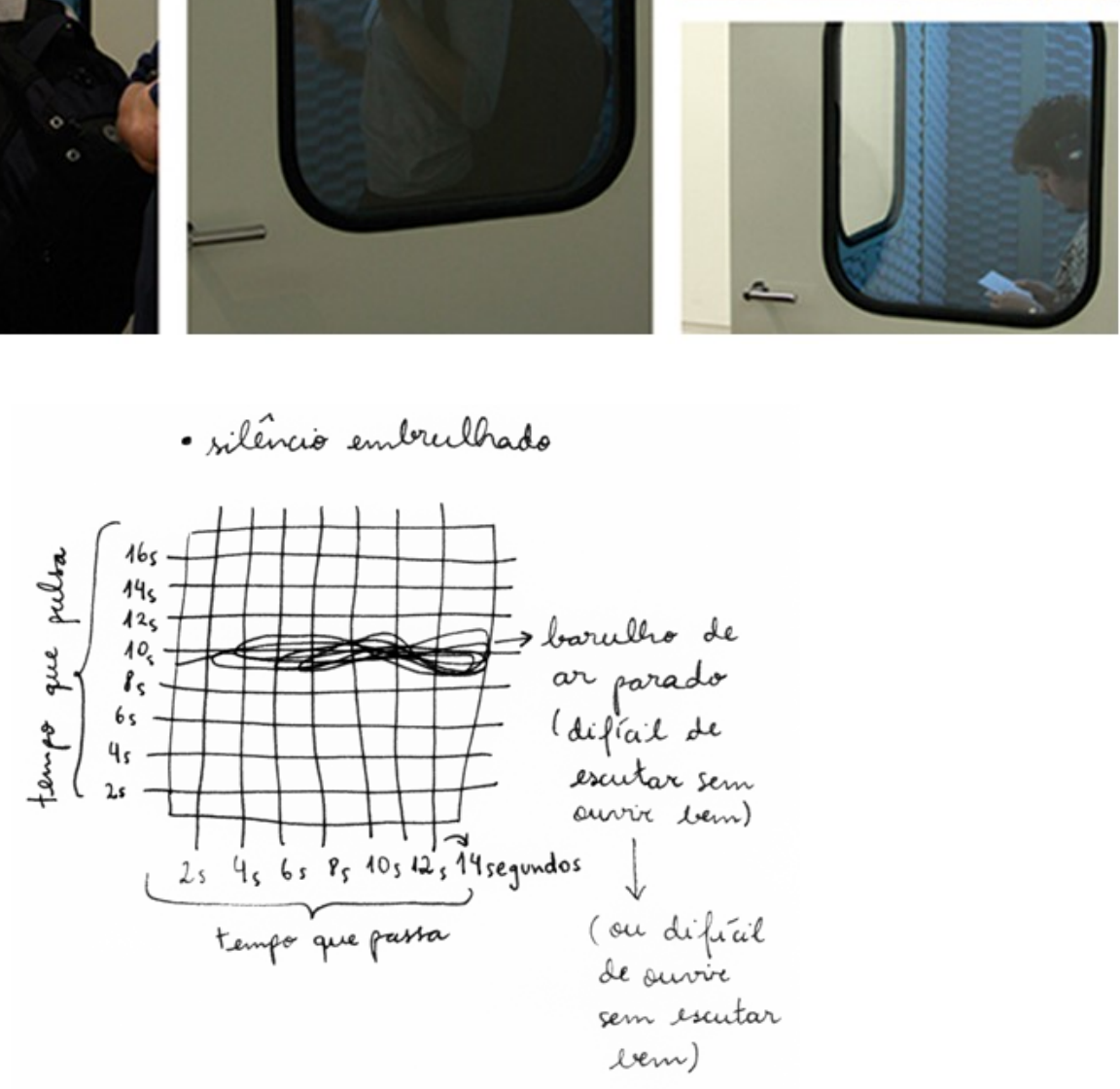

STOLF, Raquel. Areia movediça, [Sala de escuta], Fundo do ar. Crítica Cultural - Critic, Palhoça, SC, v. 11, n. 2, p. 225-239, jul./dez. 2016. 
- silencio pendurado

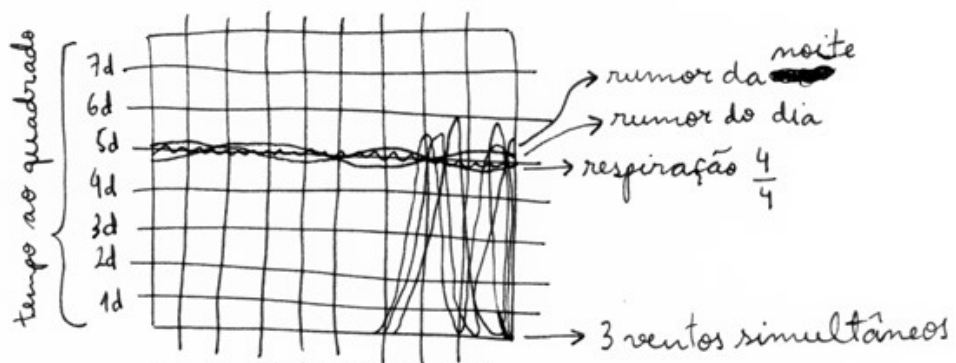

$\underbrace{1 d 2 d \text { id } 4 d \text { Sd } 6 d \text { Fd 8dias }}_{\text {tempo quadrado }}$

- silêncio (quase) desmaiando

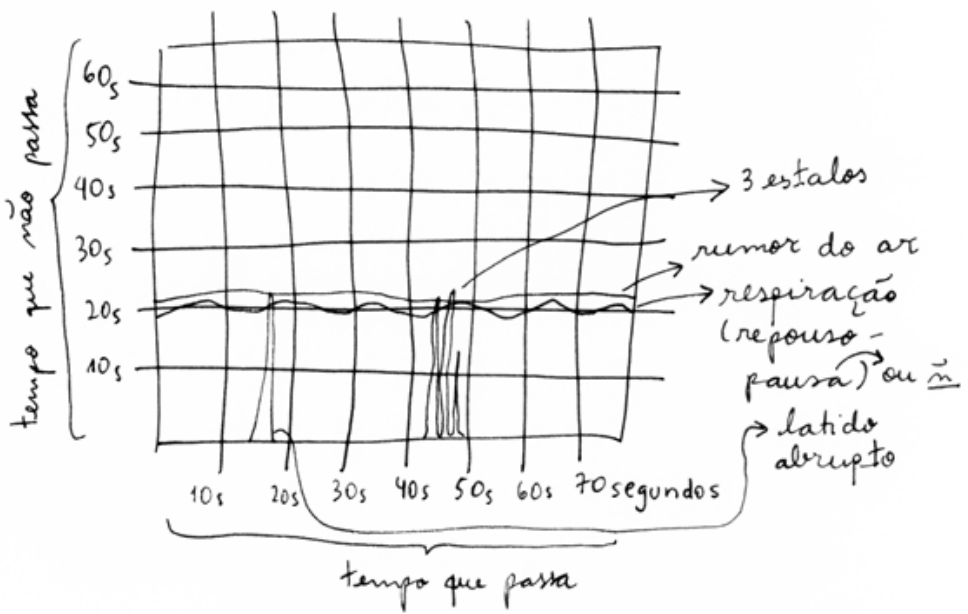




\section{Fundo do ar [caderno-abismo] ${ }^{3}$}

o presente bloco pode ser lido em sub-voz, em

espaços fechados, com ou sem respirações auditivas 


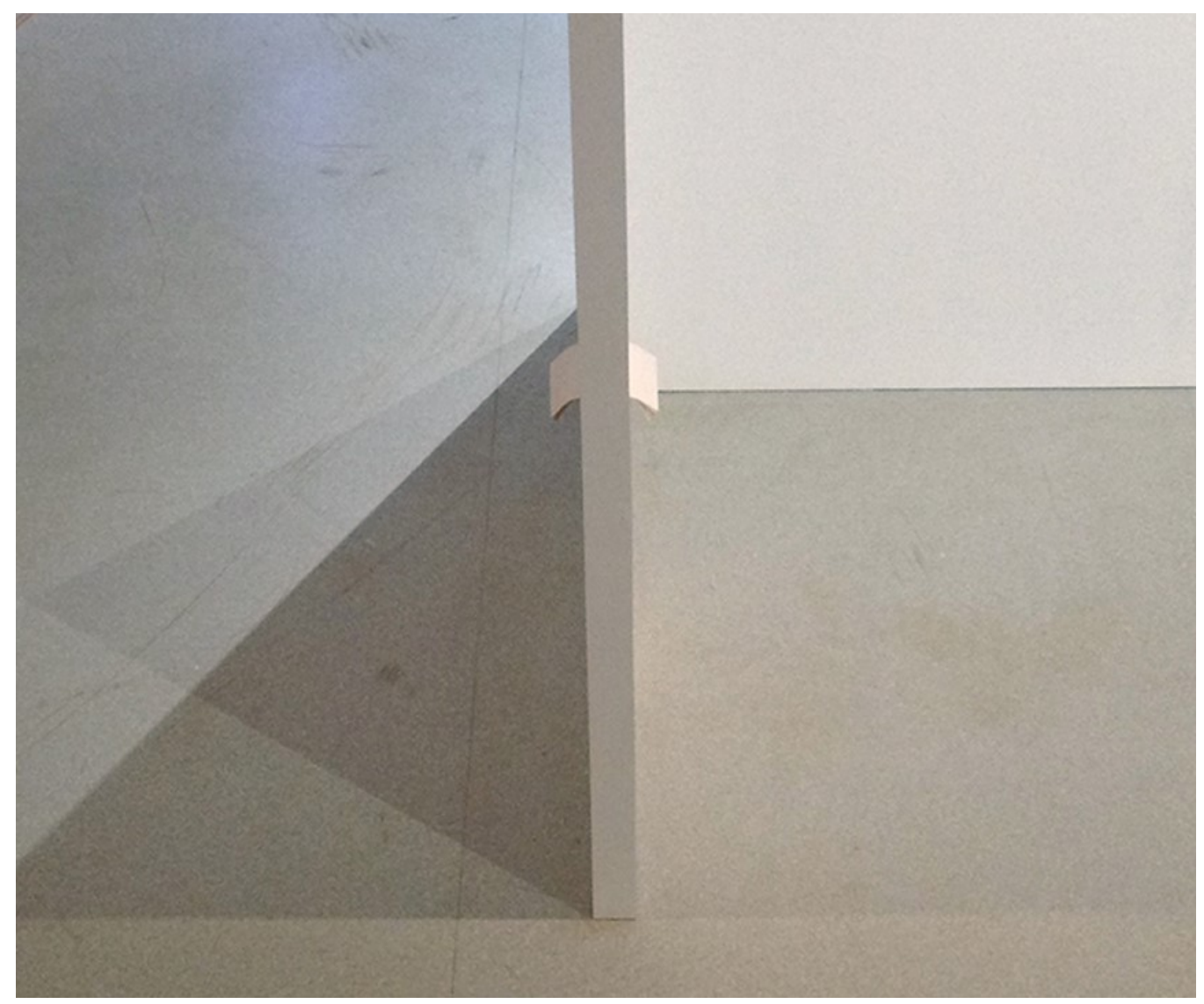


como manter uma coleção de cadernos em branco?

penso no estado antes da escrita, num estado antes/entre/depois

do gesto de escrever ou de uma escrita em sub-voz:

sub-voz = nuvem alta [nuvem-ar]

sob-voz = nuvem média [nuvem-nuvem]

sobre-voz $=$ nuvem baixa [nuvem-solo]

não-voz = não-nuvem [intranuvem]

nessa espécie de silêncio (que pode se assustar ou mesmo assustar alguém),

a relação entre escrita e escuta pode ser uma relação sem medida

(de volume e de velocidade), oscilando entre imobilidade e rumor.

para existir uma rasura ou um rumor, é preciso que alguma escrita

aconteça ou que alguma palavra tente acontecer.

mas, como não distender/dilatar a voz? como sair e voltar?

como arrastar o fundo ou escutar uma rasura-flashback?

no fundo do ar talvez aconteça uma crosta de silêncio.

o fundo do ar não é localizável.

o intervalo pode ser a indicação ou o sinal de pista para algum

plano de partida ou para algum outro vazio.

tentando pensar sobre a pausa, percebo o intervalo como apontamento.

o intervalo como uma escrita ou como escuta/esculta. 
${ }^{1}$ Extrato do texto-obra Areia movediça, publicado no Jornal de Borda n.1 (ed. Fernanda Grigolin, Ediciones Costeñas), São Paulo, p. 4-5, 01 mar. 2015.

${ }^{2}$ Assonâncias de silêncios [sala de escuta] (2008-2010) consiste numa instalação composta por uma cabine de aço com isolamento acústico de $40 \mathrm{~dB}$, equipada com um abafador de ruído (24 dB), lâmpada e banqueta (parte interna), com distribuição de três tipos de material impresso sobre prateleira externa.

- Projeto do trabalho e anotações de processo.

- Fotos de Helder Martinovsky: vista e detalhes do trabalho na exposição individual Assonâncias de silêncios, no Museu de Arte de Santa Catarina, em Florianópolis, 2011.

Acervo: Museu de Arte de Santa Catarina - MASC.

- Detalhes de notas-desenhos em impressos distribuídos na instalação.

${ }^{3}$ Fundo do ar [caderno-abismo] (2013-2015) consiste numa instalação composta por um caderno em branco que atravessa uma fresta/buraco na parede.

- Fotos de Raquel Stolf: vista e detalhes da instalação na exposição coletiva do Prêmio CNI - SESI - SENAI Marcantonio Vilaça (2014-2015), no MAC-USP Ibirapuera, em São Paulo, 2015.

\section{Recebido em 10/09/16. Aprovado em 12/11/2016}

Title: Areia movediça, [sala de escuta], Fundo do ar

Abstract: Some extracts of three artworks developed by me: Areia movediça (text-work published in the Jornal de Borda n.1, 2015); Assonâncias de silêncios [sala de escuta] (sound installation, 2008-2010) and Fundo do ar [caderno-abismo] (installation, 2013-2015). In the process of these artworks are investigated relations between writing processes and situations of reading and listening (or "species of listening", modulations between sonorous and acoustic), at intersections between word and silence (in attempts to void's propositions), also thinking their immobilities/passages (or their immobile passages) and their opacities.

Keywords: Writing processes. Listening situations. Silence. Noise. Void.

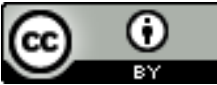

Este texto está licenciado com uma Licença Creative Commons Atribuição 4.0 Internacional. 